\title{
Supply Chain Management of Fruits and Vegetables: Realities and Prospects
}

\author{
Kamola Mukhammedjanova (Tashkent State University of Economics, Uzbekistan)
}

\begin{abstract}
Fruit and vegetables are an important sector of agricultural production in Uzbekistan, because they provide the population with sufficient food, as well as income for rural households. Despite this, there are a number of problems in terms of storage, harvesting, processing, and transportation dealing with supply chain management of fruits and vegetables. This article examines the existing mechanism of fruit and vegetables supply chain, as well as offers optimal solutions concerning these issues. In this research there were used secondary data collected from official statistics and professional literatures. As methods of research were used analysis and synthesis, comparison. By practicing improved supply chain management mechanism, there will be significant reduction in the wastages of fruits and vegetables which in turn will benefit both the farmers also the consumers by means of increased returns and decrease in prices respectively.
\end{abstract}

\section{Introduction}

Agriculture is the leading and priority sector of the economy of Uzbekistan and plays an important role in ensuring social, economic stability and food security of the country. Agriculture is the leading and priority sector of the economy of Uzbekistan and plays an important role in ensuring social, economic stability and food security of the country. In Uzbekistan, there is a significant potential for export of fresh and processed fruit and vegetable products to foreign markets. Our country is famous for its vegetables, fruits, grapes, melons, many kinds and varieties of which are unique in their exquisite taste. It is the unique taste qualities of Uzbek fruit and vegetable products, conditioned by good climatic conditions, and determine its high competitiveness in the world markets of agricultural food products. To date, domestic fruit and vegetables in fresh and processed form are supplied to more than 50 countries around the world. In 2017, the volume of exports of fruit and vegetable products amounted to 918.08 thousand tons worth $\$ 665.9$ million, and this figure is planned to be increased by $30 \%$ in this year (SSC of the Republic of Uzbekistan, 2018)

\section{Descriptive Statistics}

According to preliminary data, the total agricultural production in January-December of 2017 increased by $101.9 \%$ compared with the corresponding period in 2016, including dehkan farms accounted for $100.7 \%$. Also, in all types of farms it is harvested 3014.6 thousand tons of potatoes (101.9\% against January-December 2016$)$, 11 433.6 thousand tons (101.4\% ) - vegetables, 3076 - 3 thousand tons (101.1\%) - fruits and berries and 1748.9 thousand tons $(100.8 \%)$ of grapes.

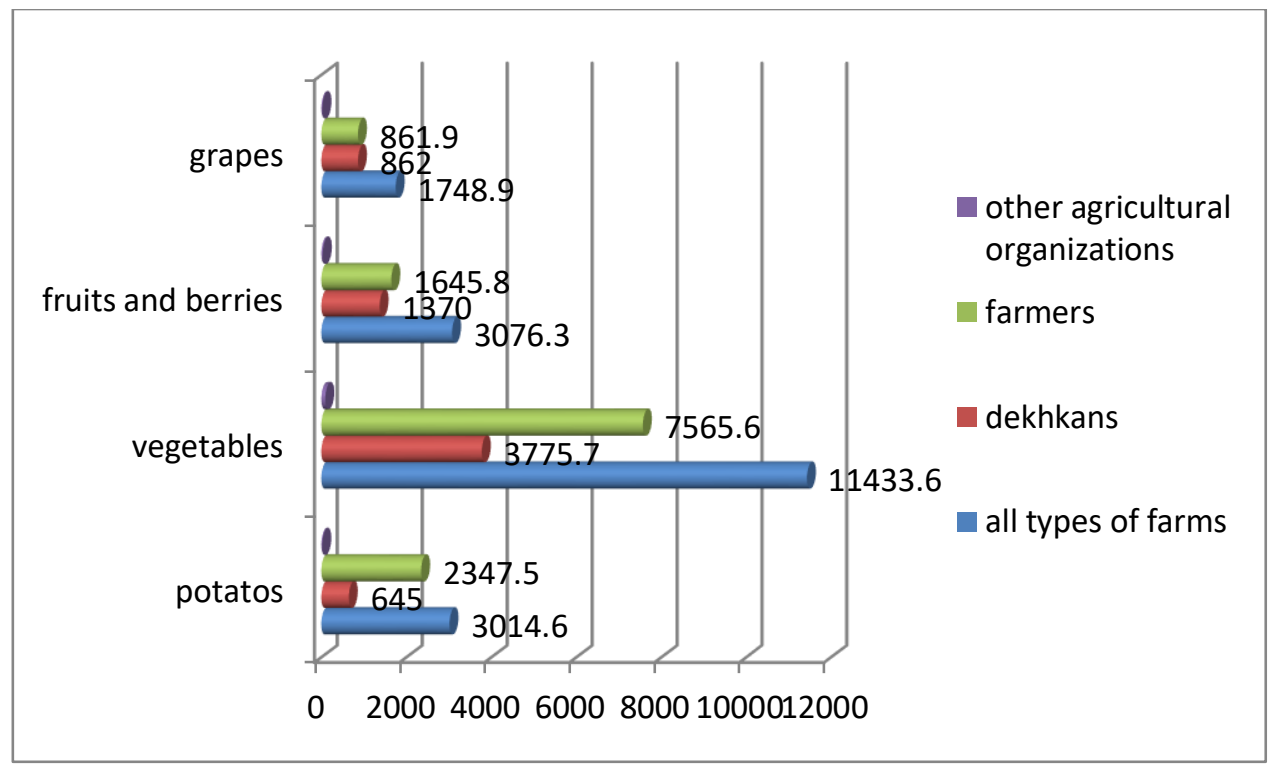

Figure 1. Production of Main Types of Agricultural Products by Categories of Farms in January-December of 2017( in billion.soums) 
It can be seen from the figure, dekhkans (private subsidiaries) remain the main producers of many types of agricultural products, during the reporting period they produced $77.9 \%$ of potatoes, $66.2 \%$ of vegetables and $53.5 \%$ of fruits and berries.

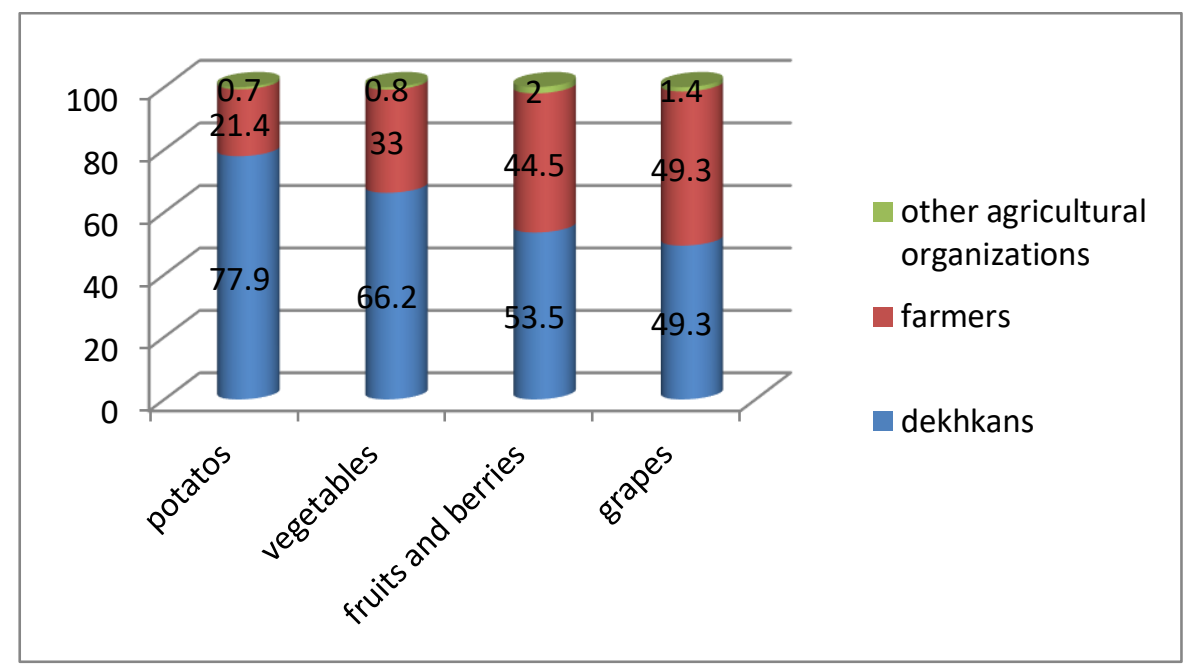

Figure 2. Share of Households in the Production of Basic Agricultural Products (in \%)

Compared to the end of 2017, the reason for fluctuations in the prices of fruits and vegetables is that they are mainly related to seasonal factors. Prices for grain increased by $31.4 \%$ to $57.7 \%$, apples - by $42.1 \%$, dried fruits by $11.5 \%$ and bananas by $9.6 \%$. During the quarters, prices for vegetables increased by an average of $11.5 \%$, and cucumbers and tomatoes in a significant ratio $(25.3 \%$ and $19.5 \%)$. Prices for some vegetable products decreased. In this case, onion fell by $7.2 \%$, carrots - by $2.3 \%$ and prices for cabbage - by $1.0 \%$. The price of potatoes decreased on average by $0.8 \%$ on average over three months. Attraction of investments in the storage and transportation of fruits and vegetables plays an important role in the formation of a modern logistics system through the creation of multimodal trade and logistics centers that are geographically close to the main centers for fruit and vegetable production. In the structure of investments to fixed assets by types of economic activity, investments in the storage and transportation system amounted to $10.5 \%$ in 2016 and $8.7 \%$ in 2017.

\section{Main Challenges of Fruit and Vegetable Sector}

Currently more than $51 \%$ of populations of Uzbekistan live in rural areas. However, the share of agricultural products in the country's GDP does not exceed 17 percent. The volume of processing of agricultural products does not exceed $10 \%$. The export of fruits and vegetables, which make up the bulk of agriculture, is currently $\$ 1.5-2$ billion. But in this area, there is an opportunity to export 10-15 billion dollars a year. As noted above, $4.1 \%$ decrease compared to 2016 was observed during transportation and storage of fruit and vegetable products. Most of the export of fruit and vegetable products is accounted for by road transport. The volumes, timing and cost of supply of Uzbek fruit and vegetable products largely depend on the availability of transportation of other countries. However, the existing fleet of refrigerated trucks does not cover the need for export. Transportation costs vary greatly depending on the season and availability of transport, which does not allow ensuring stability in the supply of export products. Due to the imperfection of the procurement system, grading, storage and transportation, in a short, lack of management of supply chain significant volumes of fruit and vegetable produce do not reach the consumer every year. The fruit and vegetable supply chain is characteristically complex and complicated. More than the transportation and logistics, there are other factors which impact the supply chain. Most of these products are highly perishable, strongly price volatile and uncertain on demand. Supply side is marred by seasonality, cyclicality and climatic conditions of different geographies.

\subsection{Supply Chain Management}

Supply chain management is logistics aspect of a value delivery chain. It comprises all of the parties that participate in logistics process Manufacturers, Wholesalers, Third Party Specialists like Shippers and Retailers etc. The logistics is the total process of planning, implementing and coordinating the physical movement of merchandise from manufacturer to retailer to customer in the timeliest effective and cost efficient manner possible. Logistics regards order processing and fulfillment, transportation, warehousing, customer service and inventory management as interdependent functions in the value delivery chain.

\subsection{Possible Solution}

The research conducted on the Supply chain of Fruits and Vegetables in Uzbekistan suggest that there is a shortage in supply chain management, lack of storage infrastructure which are leading to maximum inefficiencies 
and resulting to losses and wastage of fruit and vegetable products. It is planned to create "National Logistics Portal" in order to prevent product losses in the process of storage and transportation.

\section{Methodology and Results}

Considering the management of supply chains, it is necessary to distinguish the idea proposed by J. Shapiro about the division of all models of the SCM class into several groups:

- transactional, which are associated with the accumulation, processing and consistency of the initial information about the company's supply chain with the formation and dissemination of reports that would summarize such data;

- analytical, which assess the problems of supply chain planning, resorting to the possibilities of descriptive and normative (optimization) models (J. Shapiro, 2006).

A. Bochkarev was proposed a hierarchical classification of supply chain management models. Due to the classification of the supply chain management model developed by him, it becomes possible to more deeply understand the scope of application and use of various models (A. Bochkarev, 2008). Models of the top level of the hierarchy were proposed to be distributed "according to business functions" into the following types:

- cost accounting models (transactional);

- models of operations (analytical).

The subsequent classification was created only for those models of operations, which at the next level of the hierarchy must be divided "by degree of certainty" into the following classes:

- deterministic (optimization);

- probabilistic (stochastic).

Models at the third level of the hierarchy, A. Bochkarev was suggested to divide into groups "according to mathematical properties". At the same time, deterministic or optimization models are subdivided into linear, nonlinear and multi-purpose models. In turn, probabilistic or stochastic models are divided into:

- decision-making models;

- simulation models;

- prediction models;

- queuing model.

Linear optimization models at the next fourth level were proposed to be divided according to the "covered time interval":

- static (models that cover a single time period);

- dynamic (models that cover several time periods).

Linear optimization models at the fifth level are proposed to be divided into subgroups, depending on the type of objective function and constraint.

V. Lukinsky was suggested to divide methods and models into several classes in order to find a simpler connection between methods and models with the solution of a particular problem. The first class covers models and methods that are designed to solve problems under conditions of certainty, without constraints from the external environment (V. Lukinsky, 2008). The second class is represented by models of supply chain management, i.e. Models in terms of risk and uncertainty, but without competition. The third class is represented by models and methods of solving logistics tasks in a competitive environment. The subsequent classification is described below, it involves the introduction of the following types of methods and models.

- methods and models of the first kind extend to some logistical operations and functions.

- methods and models of the second kind extend to two or more operations and functions.

The purpose of methods and models of the third type is to cover the entire logistics system.

In this article it is used ordinary last squares regression model in StataSe 12 program.

\subsection{Data}

In this research there were used secondary data from Management, Organization and Innovation Survey (MOI). Survey was implemented in partnership with the World Bank and assesses management practices in 1,800 manufacturing establishments with between 50 and 5000 employees in 10 transition countries (Belarus, Bulgaria, Kazakhstan, Lithuania, Poland, Romania, Russia, Serbia, Ukraine and Uzbekistan) as well as Germany and India (World Bank, 2010). 


\subsection{Data Management}

There are various ways to get descriptive statistics about variable. Sum command is most used to know basic information about variables.

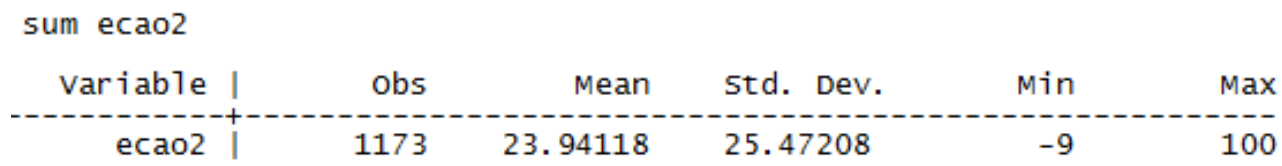

Table 1. Sum of the Variable ecao2 in StataSE12 Source: MOI survey.

From the set of enumerated data, the dependent factor is chosen, and it is the percentage of annual sales accounted for by new product and service introduced in last 3 years (symbolic ecao2). In "Table 1." from the program StataSE 12, it can be seen that the question whether the implementation of "National Logistic Portal" service can improve the Supply Chain system of fruit and vegetable sector. Sum can show the number of respondents, average statistics, standard deviation, minimum and maximum indicators by factor.

\begin{tabular}{|c|c|c|c|c|c|}
\hline variable | & obs & Mean & std. Dev. & Min & $\operatorname{Max}$ \\
\hline ecao4 | & 714 & 1. $26 \mathrm{e}+09$ & 3. $33 \mathrm{e}+10$ & -9 & 8. $89 e+11$ \\
\hline \multicolumn{6}{|l|}{ sum ecao6 } \\
\hline variable | & obs & Mean & std. Dev. & Min & $\operatorname{Max}$ \\
\hline ecao6 & 1777 & 27.59482 & 25.74752 & -9 & 100 \\
\hline
\end{tabular}

Table 2. Sum of the Variables ecao4, ecao6 in StataSE12 Source: MOI survey.

sum $13 a$

$\begin{array}{rccccr}\text { Variable | } & \text { Obs } & \text { Mean } & \text { Std. Dev. } & \text { Min } & \text { Max } \\ -13 a \mid & 1777 & 185.7974 & 313.655 & -9 & 4350\end{array}$

sum $13 \mathrm{~b}$

\begin{tabular}{cccccr} 
Variable | & obs & Mean & Std. Dev. & Min & Max \\
\hline $13 b$ | & 1777 & 71.05121 & 134.5514 & -9 & 1800
\end{tabular}

sum mois9d

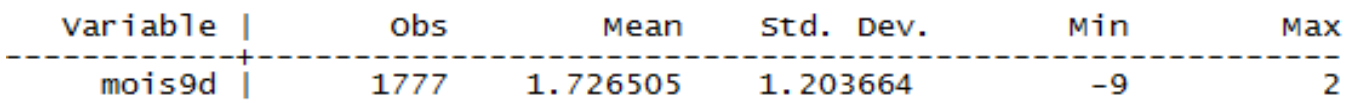

Table 3. Sum of the Variables 13a, 13b, mois 9 in StataSE12 Source: MOI survey.

sum moio10b



sum moio11b

\begin{tabular}{|c|c|c|c|c|c|}
\hline variable | & obs & Mean & std. Dev. & Min & $\max$ \\
\hline moio11b | & 164 & 24.91463 & 31.14845 & -9 & 10 \\
\hline
\end{tabular}

sum c23

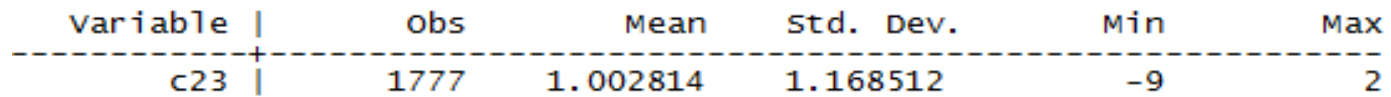

Table 4. Sum of the Variables moio10b, moiol1b,c23 in StataSE12 Source: MOI survey.

In the same way, other indicators that were selected as factors affecting to the percentage of annual sales accounted for by new product and service introduced in last 3 years had analyzed. In particular, they are, does management ask workers for their opinion on making investment (mois9d), in last fiscal year how much did 
organization invest on research and development activity (ecao4), what percentage of production is produced for this establishment by other companies (moi10b), number of production employees (13a), number of nonproduction employees (13b), what percentage of employees regularly use computers (ecao6), does this establishment has highspeed internet connection (c23).

\begin{tabular}{|c|c|c|c|c|c|c|c|}
\hline & ecao 2 & ecao 4 & ecao6 & $13 a$ & $13 b$ & moiolob & moio11b \\
\hline $\begin{array}{r}\text { ecao2 } \\
\text { ecao4 } \\
\text { ecao6 } \\
13 \mathrm{a} \\
13 \mathrm{~b} \\
\text { moio10b } \\
\text { moio11b } \\
\text { mois9d } \\
\text { c23 }\end{array}$ & $\begin{array}{r}1.0000 \\
0.1925 \\
0.2247 \\
-0.0159 \\
-0.0218 \\
0.3419 \\
0.1579 \\
-0.0892 \\
0.0101\end{array}$ & $\begin{array}{r}1.0000 \\
-0.0369 \\
0.2383 \\
0.3834 \\
-0.0833 \\
0.0408 \\
0.0567 \\
0.0134\end{array}$ & $\begin{array}{r}1.0000 \\
-0.0455 \\
0.0550 \\
0.1916 \\
0.1092 \\
0.0557 \\
0.1405\end{array}$ & $\begin{array}{r}1.0000 \\
0.8476 \\
0.0054 \\
0.1200 \\
-0.0001 \\
0.0874\end{array}$ & $\begin{array}{l}1.0000 \\
0.0257 \\
0.1203 \\
0.0483 \\
0.0745\end{array}$ & $\begin{array}{l}1.0000 \\
0.4329 \\
0.0622 \\
0.0378\end{array}$ & $\begin{array}{l}1.0000 \\
0.0186 \\
0.0363\end{array}$ \\
\hline & mois $9 \mathrm{~d}$ & $c 23$ & & & & & \\
\hline $\begin{array}{r}\text { mois } 9 d \\
\text { c23 }\end{array}$ & $\begin{array}{r}1.0000 \\
-0.0867\end{array}$ & 1.0000 & & & & & \\
\hline
\end{tabular}

Table 5. Testing for Correlation of Variables in StataSE 12 Source: MOI survey.

The next stage is testing for correlation these factors with the main dependent variable which is carried out with corr command by using correlation, several factors can be excluded that show low influence. In our case, they are 13a, 13b, mois9d, c23.

\begin{tabular}{|c|c|c|c|c|c|c|}
\hline Source | & ss & $d f$ & MS & & \multirow{3}{*}{\multicolumn{2}{|c|}{$\begin{array}{llr}\text { Number of obs } & = & 90 \\
\mathrm{~F}(4, \mathrm{85}) & = & 5.12 \\
\text { Prob }>\mathrm{F} & = & 0.0010 \\
\text { R-squared } & = & 0.1941 \\
\text { Adj R-squared } & = & 0.1562 \\
\text { Root MSE } & = & 24.262\end{array}$}} \\
\hline $\begin{array}{r}\text { Mode1 } \\
\text { Residua1 }\end{array}$ & $\begin{array}{l}12049.8661 \\
50035.9561\end{array}$ & $\begin{array}{rr}4 & 301 \\
85 & 588\end{array}$ & $\begin{array}{r}46653 \\
658307\end{array}$ & & & \\
\hline Tota1 | & 62085.8222 & 697 & 593508 & & & \\
\hline ecao2 & coef. & std. Err. & $t$ & $P>|t|$ & [95\% conf. & Interval] \\
\hline $\begin{array}{r}\text { ecao4 } \\
\text { ecao6 } \\
\text { mojo10b } \\
\text { moio11b } \\
\text { _cons }\end{array}$ & $\begin{array}{r}7.49 \mathrm{e}-09 \\
.1673087 \\
.3775053 \\
-.0155747 \\
13.64323\end{array}$ & $\begin{array}{l}3.24 \mathrm{e}-09 \\
.0973597 \\
.1242144 \\
.1137079 \\
5.26454\end{array}$ & $\begin{array}{r}2.32 \\
1.72 \\
3.04 \\
-0.14 \\
2.59\end{array}$ & $\begin{array}{l}0.023 \\
0.089 \\
0.003 \\
0.891 \\
0.011\end{array}$ & $\begin{array}{r}1.06 \mathrm{e}-09 \\
-.0262684 \\
.1305339 \\
-.2416565 \\
3.175913\end{array}$ & $\begin{array}{l}1.39 \mathrm{e}-08 \\
.3608859 \\
.6244767 \\
.2105072 \\
24.11055\end{array}$ \\
\hline
\end{tabular}

Table 6. Regression of the Factors in StataSE 12 Source: MOI survey.

From this table, it is statistically significant to say that, there is impact of chosen factors to dependent variable. In other words, probability estimated to 0.0010 , which is less than 0.05 , consequently we can accept testing hypothesis (Hypothesis-implementation of "National Logistic Portal" service can improve Supply Chain Management system of fruit and vegetable products)/

There are several models explaining Supply Chain Management performance of fruit and vegetable products. In this paper we present ordinary least squares model using data from Management, Organization and Innovation (MOI) Survey. The following model is found appropriate to estimate, whether implementation of "National Logistic Portal" project will give expected results.

$\mathrm{Y}=13.64+7.49 \mathrm{I}+0.16 \mathrm{C}+0.17 \mathrm{P}+0.01 \mathrm{OP}+\mathrm{E}$

Where,

Y - Percentage of annual sales accounted for by new product and service introduced in last 3 years

I - In last fiscal year how much did organization invest on research and development activity

$\mathrm{C}$ - What percentage of employees regularly use computers

$\mathrm{P}$ - What percentage of production is produced for this establishment by other companies

OP-What percentage of outsourced production is conducted in another country

E - Error term

This OLS model can be described as, to the independent variable Y which is percentage of annual sales accounted for by new product and service influence several factors. The investment on research and development factor (I) 
is highlights the highest impact on dependent variable (Y). It is obvious that, the research and development refers to the work a business conducts toward the innovation, introduction its products and services. Thus, implementation of new service as "National Logistic Portal" can give significant results in improving current issues of Supply Chain Management of fruits and vegetables.

\section{Conclusion}

The research conducted on the Supply chain of Fruits and Vegetables in Uzbekistan suggest that there is a shortage in supply chain management, lack of storage infrastructure which are leading to maximum inefficiencies and resulting to losses and wastage of fruit and vegetable products. Uzbekistan's fruits and vegetables sector is a very growing and presents a huge opportunity for the agribusiness and the development of the rural areas through a well-established supply chain. However, there are various factors affecting to the supply chain as discussed above which constitutes challenges for this sector and are affecting the growth of the development of Uzbekistan. As a solution it is given to implement a new service (product) "National Logistic Portal"

\section{References}

- $\quad$ "Conditions, methods of processing and storage of fruits and vegetables, internal and external marketing" teaching manual "Tafakkur", 2016.

- Blackburn, J., \& Scudder, G. (2009). Supply chain strategies for perishable products: the case of fresh produce. Production and Operations Management, 18 (2), 129-137.

- Bochkarev A. Planning and modeling of the supply chain. - Alfa-press, 2008 - 192 with.

- Edward Frazelle, Supply Chain Strategies, McGraw-Hill, 2002

- Lukinsky V.S. Models and methods of the theory of logistics. - St. Petersburg: Peter, 2008. - 448s.

- Shamis VA, Mochalin SM Some Aspects of Imitation Modeling in Logistics // Science of the 21st Century: Experience of the Past - A Look into the Future: Materials of the Intern. scientific and practical work. conference / Siberian State Automobile and Highway Academy (SibADI). - Omsk, 2015. - P. 369-373.

- Shapiro J. Modeling the supply chain - SPb.: Peter, 2006 - 720 pp.

- State Statistics Committee of the Republic of Uzbekistan www.stat.uz 